\title{
Clinical Effects of Treatment for Hypogonadism in Male Adolescents with Prader-Labhart-Willi Syndrome
}

\author{
Urs Eiholzer Jürgen Grieser Michael Schlumpf Dagmar l'Allemand \\ Institute Growth Puberty Adolescence, Zürich, Switzerland
}

\section{Key Words}

Prader-Labhart-Willi syndrome $\cdot$ Hypogonadism •

Puberty - Human chorionic gonadotropin therapy •

Lean mass $\cdot$ Fat mass $\cdot$ Body composition

\begin{abstract}
Background: In boys with Prader-Labhart-Willi syndrome (PWS), hypogonadism causes pubertal arrest and reduces pubertal muscle growth. Formerly, it was assumed that therapy with gonadal hormones accentuates behaviour abnormalities in PWS. Our aim was to assess the clinical effects of human chorionic gonadotropin (hCG) therapy on pubertal development, muscle mass and behaviour in adolescents with PWS. Methods: 6 peripubertal boys with PWS undergoing long-term treatment with growth hormone were examined 6-monthly for at least 2 years before and after pubertal arrest (13.5 \pm 0.3 years, mean \pm SEM) and the beginning of hCG therapy (500-1,500 IU twice weekly, intramuscularly). Height, weight, pubertal stage, bone age, body composition (by dual-energy X-ray absorptiometry), testosterone levels and behaviour abnormalities (obtained from parents) were assessed. Results: Testicular volume and lean mass were reduced in pubertal boys with PWS. During hCG therapy, testosterone levels and lean mass significantly increased (at the beginning and after 2 years of hCG therapy: $2.3 \pm 0.9$ and $10.7 \pm 1.3 \mathrm{nmol} / \mathrm{l},-3.1 \pm 0.3$ and $-1.4 \pm 0.6 \mathrm{SD}$, respective-
\end{abstract}

ly), and fat mass stabilized at $38 \%$. The characteristically observed PWS-associated problems, mood instability, aggressiveness and difficulties in social interaction, did not deteriorate during therapy. Conclusion: In the present study, timely application of hCG to treat hypogonadism in boys with PWS promoted virilization and normalized muscle mass without detrimental effects on behaviour. Larger studies comparing hCG therapy with testosterone replacement would be useful.

Copyright $\odot 2007$ S. Karger AG, Basel

\section{Introduction}

The Prader-Labhart-Willi syndrome (PWS) is a defined genetic disorder characterized by mental retardation, behaviour problems and a hypothalamic dysfunction [1], combined with specific dysmorphisms [2]. The hypothalamic dysfunction causes growth hormone $(\mathrm{GH})$ deficiency [3], hypogonadism [4-6] and a dysregulation of energy balance with hypoactivity $[7,8]$ and insatiable hunger [9-11], resulting in an increased fat and decreased lean body mass $[12,13]$. In addition to control of nutrient intake and enhancement of activity, beneficial effects of early therapy of GH deficiency in PWS have been demonstrated [14-16]: short stature is normalized and muscle mass enhanced $[8,12,17-20]$.

\section{KARGER}

Fax +41 613061234 E-Mail karger@karger.ch www.karger.com
(C) 2007 S. Karger AG, Basel

0301-0163/07/0684-0178\$23.50/0

Accessible online at:

www.karger.com/hre
Urs Eiholzer, MD

Institute Growth Puberty Adolescence

Moehrlistrasse 69

CH-8006 Zürich (Switzerland)

Tel. +41 4436437 00, Fax +41 4436437 01, E-Mail mail@childgrowth.org 
As a consequence of the specific form of hypogonadism in PWS [6], sexual maturation stops at mid-puberty. The resulting eunuchoid appearance with a high voice aggravates the handicap in male adolescents and adults with PWS. The absence of a pubertal growth spurt and an increase in muscle mass during puberty $[21,22]$ further reduce the already decreased energy expenditure $[13$, 23]. Hence hypogonadism adds to fat accumulation and morbid obesity due to the lack of pubertal muscle mass accretion in PWS males [24, 25]. So far, replacement of sex hormones in male adolescents with PWS has remained controversial because of the belief that testosterone may aggravate behaviour abnormalities in these patients [26, 27]. PWS is characterized by a specific behaviour profile comprising obsessions/compulsions, inflexibility and temper tantrums [28, 29], in addition to a mild intellectual disability with a mean IQ of 60 points $[30,31]$. Moreover, psychotic episodes occur in about $20 \%$ of young adults and are more frequent in patients with maternal uniparental disomy (UPD) [32, 33]. Adolescence is a critical period in PWS due to an increase in disruptive or antisocial behaviour and in emotional disturbances [34].

Very recently, based on the identical group of male adolescents, we have demonstrated that hypogonadism in male subjects with PWS has gonadal and hypothalamic components [6]. The present paper focuses on sexual maturation, body composition and behavioural changes during human chorionic gonadotropin (hCG) treatment in PWS.

\section{Materials and Methods}

\section{Patients and Design of the Study}

Six peripubertal boys with genetically proven PWS ( 4 with maternal UPD and 2 with paternal deletion of chromosome 15) were examined every 6 months between the age of 7 and 17 years by the first author.

All boys were on long-term (mean 44 months, range 12-84) daily treatment with recombinant human GH (Genotropin ${ }^{\circledR}$, Pfizer, Dübendorf, Switzerland, $0.025 \mathrm{mg} / \mathrm{kg} / \mathrm{day}$, corresponding to approximately $6 \mathrm{mg} / \mathrm{m}^{2} /$ week) and their height and IGF-I levels had normalized. At a bone age of 13-15 years, the induction of puberty was started by therapy with hCG (Pregnyl ${ }^{\circledR}$, Organon, Pfäffikon SZ, Switzerland), namely for bone ages from 13 to 13.5 years with 500 IU hCG twice weekly, intramuscularly; for bone ages from 13.6 to 14.5 years with 1,000 IU twice weekly, intramuscularly, and for bone ages above 14.5 years with 1,500 IU twice weekly, intramuscularly. hCG injections were chosen for substitution of hypogonadism in PWS rather than testosterone undecanoate, because hCG administration can be controlled and adapted on a short-term basis preventing significant fluctuations of testosterone levels.
The study was approved by the Ethics Committee of the University of Zurich and informed consent was obtained from the parents.

\section{Measurements}

Height and weight were measured using standard techniques [35] and weight for height (WFH) was expressed as standard deviation scores (SDS, difference between patient's data and the height- and gender-related mean of the reference group divided by the height- and gender-related standard deviation of the reference group) to adjust for age and gender. Growth velocity per year was calculated from 6 monthly intervals. In 1 boy, growth velocity could not be measured because he had scoliosis surgery while being on hCG injections. Pubertal stage was assessed every 6 months as suggested by Tanner. Testicular volume was measured using a Prader orchidometer and indicated as mean of the left and right testicular volume. One boy with secondary ascent of the testes was cryptorchid at the start of hCG therapy, all other boys had intrascrotal testes after surgical intervention during infancy. Bone age was determined by X-ray [36] at 12-month intervals.

Body composition was determined by dual-energy X-ray absorptiometry [DEXA; Hologic QDR-2000, Waltham, Mass., USA, software version 7.10B, intermeasurement variation coefficient for lean mass $(\mathrm{LM})=1 \%$ and for fat mass $=2 \%$ ] before and at least every 6 months during treatment with hCG. LM was calculated as fat-free mass minus bone mineral content. Body composition was compared to reference values measured in a European population, as previously described [12]: LM and fat mass were adjusted for gender and height and expressed as SDS, using a cross-sectional study in Dutch children as reference [37].

In 1 boy, DEXA measurements could not be performed immediately or 2 years after the start of hCG therapy due to metal implants for severe scoliosis.

As there is no standardized questionnaire to assess behaviour abnormalities in adolescents with PWS, main behaviour problems as well as the changes observed during induction of puberty with hCG were assessed by a questionnaire developed by a paediatric psychiatrist experienced in caring for adolescents with PWS. The questions addressed to the parents explored (1) relations to peers; (2) sexuality; (3) aggressiveness; (4) preoccupation with one's own appearance; (5) risky behaviour; (6) retraction from social interaction; (7) mood, and (8) school performance, subdivided into a total of 19 items. Parents were also asked to compare these hCG-induced changes with those observed during spontaneous puberty in healthy brothers and sisters. The answers to each item were rated by points, ranging from 0 to +1 , with increasing seriousness of the problems before therapy. Concerning the improvement or deterioration during hCG therapy or in comparison to pubertal behaviour changes in brothers and sisters, points ranged from -1 to +1 , respectively. The more marked and deteriorating the problems were, the higher the score resulted. If the questionnaire was filled in by several adults, means of the scores in one child were used.

Data are given as means and standard errors of the mean (SEM) as well as ranges, where appropriate. Significant intra-individual changes during hCG therapy were calculated by Student's paired $t$ test and $\mathrm{p}$ values below 0.05 were considered significant. 
Table 1. Clinical, biochemical and body composition parameters in male adolescents with PWS, before and during treatment with hCG for hypogonadism

\begin{tabular}{|c|c|c|c|c|c|c|c|c|c|}
\hline & $\begin{array}{l}\text { CA } \\
\text { years }\end{array}$ & $\begin{array}{l}\text { BA } \\
\text { years }\end{array}$ & $\begin{array}{l}\text { Growth veloc- } \\
\text { ity, } \mathrm{cm} / \text { year }\end{array}$ & $\begin{array}{l}\text { Testicular } \\
\text { volume, ml }\end{array}$ & $\begin{array}{l}\text { Pubic hair } \\
\text { stage }\end{array}$ & $\begin{array}{l}\text { Testo. } \\
\text { nmol/1 }\end{array}$ & $\begin{array}{l}\text { WFH } \\
\text { SDS }\end{array}$ & $\begin{array}{l}\text { LM } \\
\text { SDS }\end{array}$ & $\begin{array}{l}\text { FM } \\
\%\end{array}$ \\
\hline \multicolumn{10}{|c|}{ Beginning of puberty ${ }^{1}$} \\
\hline $\mathrm{n}$ & 6 & 6 & 5 & 5 & 6 & 6 & 6 & 5 & 5 \\
\hline Mean & 11.2 & 12.5 & 6.8 & 2.7 & 2.5 & 1.2 & 1.70 & -3.25 & 34.6 \\
\hline SEM & 0.4 & 0.3 & 1.1 & 0.1 & 0.4 & 0.3 & 0.666 & 0.38 & 2.5 \\
\hline Min. & 10.1 & 11.3 & 4.0 & 2.5 & 1.0 & 0.3 & -0.52 & -4.30 & 28.1 \\
\hline Max. & 12.7 & 13.3 & 11.3 & 3.0 & 3.5 & 2.3 & 4.20 & -2.36 & 40.5 \\
\hline \multicolumn{10}{|c|}{ Pubertal arrest, beginning of hCG therapy ${ }^{2}$} \\
\hline $\mathrm{n}$ & 6 & 6 & 5 & 6 & 6 & 6 & 6 & 6 & 6 \\
\hline Mean & 13.5 & 13.9 & 4.7 & $4.0^{* *}$ & $4.4^{* *}$ & 2.3 & 2.59 & -3.07 & $41.0^{*}$ \\
\hline SEM & 0.3 & 0.3 & 0.8 & 1.0 & 0.4 & 0.9 & 0.90 & 0.32 & 3.2 \\
\hline Min. & 12.5 & 13.3 & 2.7 & 0.0 & 3.0 & 0.8 & -0.35 & -3.97 & 31.5 \\
\hline Max. & 14.3 & 15.5 & 6.7 & 7.5 & 5.0 & 6.9 & 6.10 & -1.95 & 52.5 \\
\hline \multicolumn{10}{|c|}{6 months after onset of hCG therapy } \\
\hline $\mathrm{n}$ & 6 & 6 & 5 & 6 & 6 & 6 & 6 & 5 & 5 \\
\hline Mean & 14.0 & 14.4 & 6.4 & 5.0 & 4.7 & 7.3 & 2.83 & -2.41 & 37.3 \\
\hline SEM & 0.3 & 0.4 & 1.4 & 0.6 & 0.2 & 1.4 & 0.89 & 0.42 & 4.1 \\
\hline Min. & 13.0 & 13.6 & 2.6 & 3.5 & 4.0 & 3.9 & 0.05 & -3.63 & 27.5 \\
\hline Max. & 14.7 & 16.3 & 9.3 & 8.0 & 5.0 & 13.0 & 6.20 & -1.35 & 51.7 \\
\hline \multicolumn{10}{|c|}{ At 2 years of hCG treatment ${ }^{3}$} \\
\hline $\mathrm{n}$ & 6 & 6 & 5 & 6 & 6 & 6 & 6 & 5 & 5 \\
\hline Mean & 15.6 & 15.5 & 3.1 & $5.3^{* *,+}$ & $5.2^{* * *,+}$ & $10.7^{* * *,++}$ & 3.1 & $-1.38^{*,+}$ & 38.1 \\
\hline SEM & 0.2 & 0.3 & 1.0 & 0.6 & 0.2 & 1.3 & 0.82 & 0.62 & 4.8 \\
\hline Min. & 14.6 & 14.3 & 1.0 & 3.5 & 5.0 & 7.1 & 1.70 & -3.24 & 28.1 \\
\hline Max. & 16.0 & 16.8 & 6.2 & 8.0 & 6.0 & 16.0 & 7.20 & 0.60 & 56.0 \\
\hline
\end{tabular}

$\mathrm{CA}=$ Chronological age $\mathrm{BA}=$ bone age Testo. $=$ testosterone level; $\mathrm{WFH}=$ weight for height; $\mathrm{FM}=$ relative fat mass as a percentage of total body weight. Significant differences: ${ }^{*} \mathrm{p}<0.05,{ }^{* *} \mathrm{p}<0.01$ and ${ }^{* * *} \mathrm{p}<0.001$ by paired test versus parameters at the beginning of puberty; ${ }^{+} \mathrm{p}<0.05$ and ${ }^{++} \mathrm{p}<0.01$ versus parameters at the beginning of hCG therapy.

${ }^{1}$ Beginning of puberty defined as Tanner genital stage G2 or increase in testosterone levels.

${ }^{2}$ Pubertal arrest defined as a halt of testicular volume, testosterone levels or bone maturation.

${ }^{3} 2,167 \pm 167 \mathrm{IU} /$ week, during ongoing therapy with $6 \mathrm{mg} \mathrm{hGH} / \mathrm{m}^{2} /$ day.

\section{Results}

Pubic hair developed normally and bone age was slightly accelerated (table 1). Puberty started at approximately 11.2 years of age. Pubertal arrest occurred at an average chronological age of 13.5 years, before voice deepening, and was manifested by a halt of testicular growth, bone maturation and testosterone secretion (table 1).

hCG replacement therapy led to a rapid and sustained increase in testosterone levels to the lower normal range as well as to adult pubic hair pattern and deepening of voice, but the testicular volume remained small (table 1). In 3 out of the 5 boys without scoliosis surgery, growth velocity accelerated in parallel with rising testosterone levels. In the 2 remaining boys with early start of puberty and peak testosterone levels of 7.3 and $7.5 \mathrm{nmol} / 1$, a spontaneous growth spurt had already occurred before pubertal arrest and was not produced by hCG therapy (table 1).

At the onset of puberty, LM was markedly decreased in all boys (fig. 1, table 1) despite continuous GH treatment. hCG therapy significantly increased LM (fig. 1, table 1$)$, namely by $0.91 \pm 0.25 \mathrm{SD} /$ year $(\mathrm{p}<0.05)$ during 2.5 years of treatment, compared to the year before pubertal arrest, when LM did not significantly rise (by 0.11 $\pm 0.12 \mathrm{SD}$ /year; n.s.). LM became normal in 4 of the 5 boys during hCG replacement therapy. 
Fig. 1. LM SDS for height of 6 boys with PWS before and after therapy with hCG, started at mean age of 13.5 years (vertical line). The means are indicated by filled circles with standard deviations and a bold line. Normal mean and lower limit of the normal range of LM SDS are indicated by broken lines. GH was continuously given for at least 1 year.

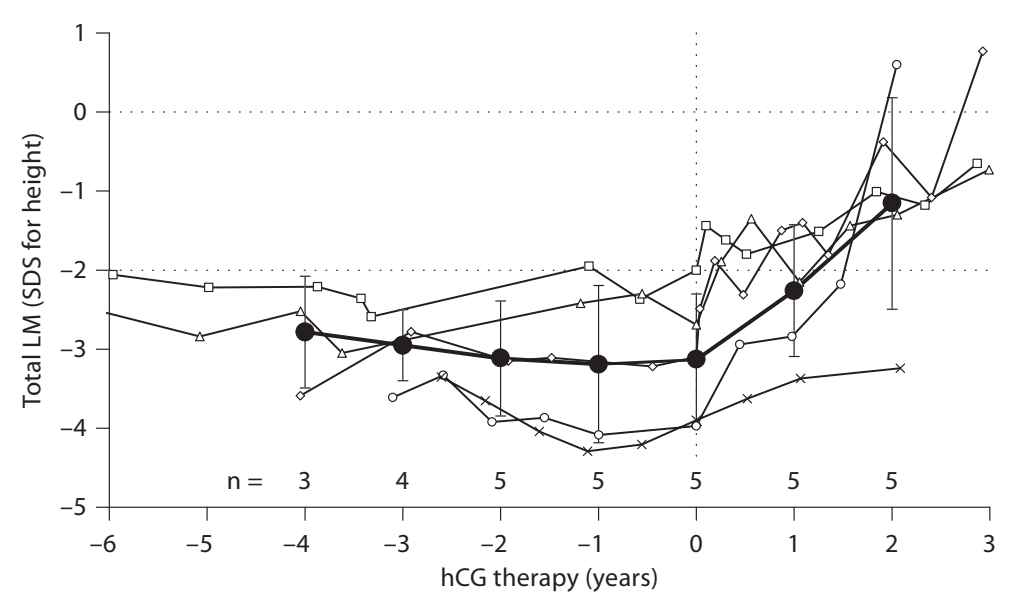

retraction, risky behaviour and school performance at a subnormal level were not assigned as a problem in PWS and were not essentially altered by induction of puberty.

The 2 boys with paternal deletion of chromosome 15 had no problems of conduct before induction of puberty and during hCG therapy, in contrast to the 4 boys with UPD. Families had 2.5 children on average, age 17.4 years (1122). In one family, the PWS boy was the only child. Within the remaining 5 families, there were 5 boys and 4 girls, the adolescent with PWS having a brother in 4/5 families.

The questions revealed 3 specific problem areas associated with the PWS patients (fig. 2): difficulties in, or lack of, social interaction were reported in 3/6 patients that did not worsen, but improved during hCG therapy in $2 / 6$ patients. There were no marked differences compared to pubertal changes in the brothers and sisters. Aggressiveness or conflicts were a fundamental problem in $3 / 6$ patients. During hCG therapy, conflicts within the family worsened in 3 of 6 boys, similar to changes in 3 of 5 pubertal brothers and sisters, but aggressive behaviour outside of the family decreased in 4/6 patients. Irritability or rapid mood changes were a problem in $3 / 6$ boys with PWS, and less stable than in pubertal brothers and sisters, but remained unaltered during therapy with hCG.

Sexual arousal was a minor problem in 1 boy only. In all other boys, sexuality was less problematic than in pubertal brothers and sisters and even became less apparent during hCG therapy. Also body image, social

\section{Discussion}

The present observational study shows for the first time the clinical effects of a replacement therapy of hypogonadism in male adolescents with PWS in addition to ongoing GH treatment. The aim of the hCG therapy was to complete male pubertal development in a physiological, well-balanced and cautious way. hCG normalizes pubertal development and muscle mass without deteriorating behaviour problems. The augmentation of muscle mass is essential to control the obesity-related metabolic risk profile in PWS [38].

Boys with PWS entered puberty at an adequate or even early age with normal levels of testosterone, as shown previously $[6,39]$. Bone maturation and testicular development stopped after bone age of 13 years as is typically seen in hypothalamic hypogonadism [40]. During hCG therapy, testosterone rose, though levels remained in the lower normal range. Adult male appearance was completed, but the mean testicular volume remained below $6 \mathrm{ml}$, and fertility was not achieved [6]. hCG treatment accelerated 


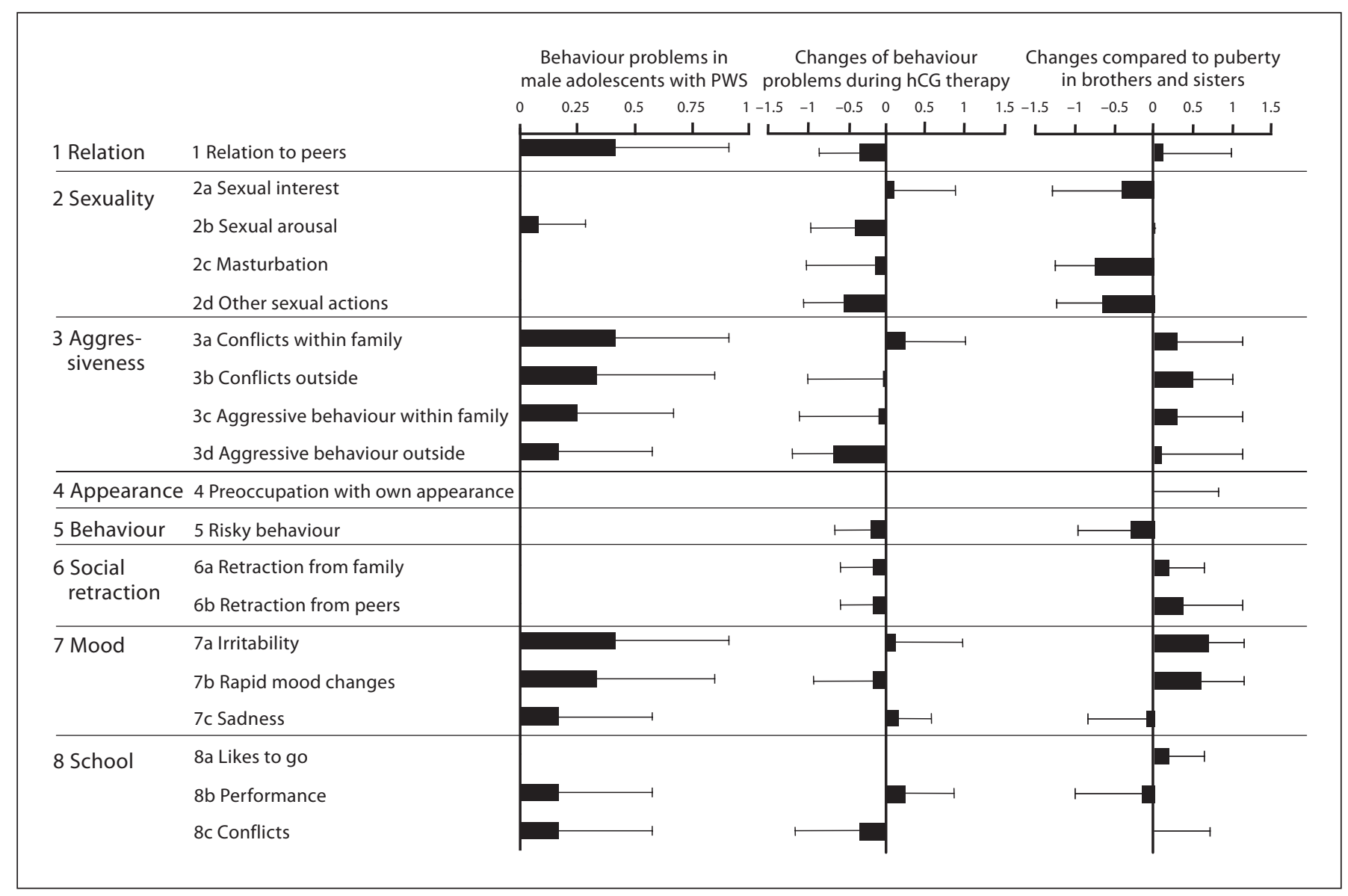

Fig. 2. Behaviour in male adolescents with PWS, assessed by a score according to a questionnaire answered by parents (means $\pm \mathrm{SD}$; refer to Materials and Methods for further explanation).

growth velocity only in boys who had not started their pubertal growth spurt spontaneously. However, our data set is too small and heterogeneous in order to draw any conclusion on the contribution of the hCG-induced pubertal growth spurt to final height.

During long-term therapy with GH, stature normalized (growth data shown elsewhere [18]), but muscle mass remained reduced in boys with PWS. Irrespective of the DEXA method used, the deficit of LM even during GH therapy was found in several studies [20,41]. At pubertal age, the addition of exogenous hCG with subsequent testosterone secretion stimulated muscle growth, as LM significantly increased into the lower normal range. Increasing LM by 0.91 SD per year over 2.5 years, the addition of hCG was as effective as $\mathrm{GH}$, because during the first 3 years of GH therapy, LM increased by $0.72 \pm 0.13 \mathrm{SD}$ per year in these boys. This observation illustrates the important interaction between GH and androgens during pu- berty, as normalization of LM can only be achieved with the combined replacement therapy.

Even while being on GH therapy, fat mass was elevated and further increased during the early stages of puberty. Only when hCG was added did fat mass stabilize, most likely as a consequence of the higher muscle mass.

The parental interviews on behaviour revealed characteristic fundamental problems associated with this disorder, mainly mood instability as well as disturbances of social interaction combined with aggressiveness. These observations are in line with larger observational studies $[42,43]$. No parents complained about heightened aggressive behaviour, serious temper tantrums or problems related to sexuality during induction of puberty in PWS patients. However, it may have affected the response of the parents knowing their son on hCG therapy. Nevertheless, the exploration with identical questions by the 
same child psychologist and the possibility to make comparisons within the same family strengthen the reported behavioural observations. Interestingly, most behaviour problems were described in boys with UPD only which is in line with earlier reports $[32,33]$. The myth that gonadal replacement may lead to a more aggressive behaviour and aggravate temper tantrums was not confirmed by our observations. Though the number of patients examined was limited due to the rarity of the syndrome (prevalence 1:15,000-25,000) [44, 45], a more generalized early treatment of hypogonadism in PWS is justified to examine prospectively the androgenic effects on behaviour in larger controlled studies.

Due to the increased knowledge and improved management of children with PWS the outcome of these patients has improved in the last years. Consequently, an optimal management of puberty is now also warranted in adolescents presenting this rare condition.

In all PWS boys with hypogonadism, adequate replacement therapy should be started when gonadal maturation is absent or stops at the age of 13-14 years [46]. All the same, it has to be borne in mind that adolescence is a critical period in PWS [34] with psychotic episodes occurring in one fifth of young adults [32, 33]. Even in healthy men, testosterone in high doses may induce psychotic disorders [47-49], but there is no study so far on whether hCG therapy bears a smaller risk in this regard than testosterone. We chose hCG injections to mimic the physiological development and to prevent significant fluctuations of testosterone levels, because former anecdotal reports $[26,27]$ suggested that behaviour problems deteriorate during testosterone treatment in PWS patients and increase the risk of psychotic exacerbation. The twice-weekly injections were not perceived as a problem, most likely due to the adaptation to daily subcutaneous $\mathrm{GH}$ injections and to the reduced level of pain sensitivity in PWS.

In conclusion, hCG therapy is an adequate treatment of hypogonadism in adolescent boys with PWS because in the present study it normalized muscle mass and adult male appearance without deteriorating behavioural problems beyond what was found in pubertal brothers and sisters. Larger studies are to be conducted to corroborate the effects of hCG on behaviour and to compare hCG with testosterone replacement.

\section{Acknowledgements}

We are obliged in memoriam to Prof. Milo Zachmann ${ }^{\dagger}, \mathrm{Zu}-$ rich, who encouraged us to study hCG treatment of hypogonadism in these boys. The advice of Meinolf Noeker, PhD, Dipl. Psychologist, Bonn, and Udo Meinhard, MD, Paediatric Endocrinologist, Zurich, is highly appreciated. We thank Mrs. Claudia Weinmann for research coordination and taking good care of the patients. We are very grateful to Dr. Lara Ogunshola, Institute of Veterinary Physiology, University of Zurich, for her help in editing the English manuscript.

\section{References}

1 Eiholzer U: Prader-Willi Syndrome. Effects of Human Growth Hormone Treatment. Basel, Karger, 2001.

-2 Gunay-Aygun M, Schwartz S, Heeger S, O'Riordan MA, Cassidy SB: The changing purpose of Prader-Willi syndrome clinical diagnostic criteria and proposed revised criteria. Pediatrics 2001;108:E92.

- 3 Eiholzer U, Bachmann S, l'Allemand D: Is there a growth hormone deficiency in Prader-Willi syndrome? Six arguments to support the presence of a hypothalamic growth hormone deficiency in Prader-Willi syndrome. Horm Res 2000;53(suppl 3):44-52.

4 Prader A, Willi H: Das Syndrom von Imbezibilität, Adipositas, Muskelhypotonie, Hypogenitalismus, Hypogonadismus und Diabetes mellitus mit 'Myatonie'-Anamnese. 2nd Int Congr Ment Retard, Vienna, 1961, pp 353-357.
5 Grugni G, Morabito F, Crino A: Gonadal function and its disorders in simple obesity and in Prader-Willi syndrome; in Eiholzer U, l'Allemand D, Zipf W (eds): Prader-Willi Syndrome as a Model for Obesity. Basel, Karger, 2003, pp 140-155.

-6 Eiholzer U, l'Allemand D, Rousson V, Schlumpf M, Gasser T, Girard J, Grüters A, Simoni M: Hypothalamic and gonadal components of hypogonadism in boys with Prader-Labhart-Willi syndrome. J Clin Endocrinol Metab 2006;91:892-898.

7 Davies PS, Joughin C: Using stable isotopes to assess reduced physical activity of individuals with Prader-Willi syndrome. Am J Ment Retard 1993;98:349-353.

-8 Eiholzer U, Nordmann Y, l'Allemand D, Schlumpf M, Schmid S, Kromeyer-Hauschild K: Improving body composition and physical activity in Prader-Willi Syndrome. J Pediatr 2003;142:73-78.
9 Holland AJ, Treasure J, Coskeran P, Dallow $\mathrm{J}$ : Characteristics of the eating disorder in Prader-Willi syndrome: implications for treatment. J Intellect Disabil Res 1995;39: 373-381.

-10 Lindgren AC, Barkeling B, Hagg A, Ritzen EM, Marcus C, Rossner S: Eating behavior in Prader-Willi syndrome, normal weight, and obese control groups. J Pediatr 2000;137:5055.

11 Hinton E, Holland A, Gellatly M, Soni S, Patterson M, Ghatei M, Owen A: Neural representations of hunger and satiety in PraderWilli syndrome. Int J Obes (Lond) 2006;30: 313-321.

12 Eiholzer U, l'Allemand D, van der Sluis I, Steinert H, Ellis K: Body composition abnormalities in children with Prader-Willi syndrome and long-term effects of growth hormone therapy. Horm Res 2000;53:200-206. 
-13 van Mil EA, Westerterp KR, Gerver WJ, Curfs LM, Schrander-Stumpel CT, Kester $\mathrm{AD}$, Saris WH: Energy expenditure at rest and during sleep in children with PraderWilli syndrome is explained by body composition. Am J Clin Nutr 2000;71:752-756.

- 14 Eiholzer U, Blum WF, Molinari L: Body fat determined by skinfold measurements is elevated despite underweight in infants with Prader-Labhart-Willi syndrome. J Pediatr 1999;134:222-225.

-15 Eiholzer U, l'Allemand D, Schlumpf M, Rousson V, Gasser T, Fusch C: Growth hormone and body composition in children younger than 2 years with Prader-Willi syndrome. J Pediatr 2004;144:753-758.

16 Carrel AL, Moerchen V, Myers SE, Bekx MT, Whitman BY, Allen DB: Growth hormone improves mobility and body composition in infants and toddlers with Prader-Willi syndrome. J Pediatr 2004;145:744-749.

- 17 Eiholzer U, Gisin R, Weinmann C, Kriemler $\mathrm{S}$, Steinert H, Torresani T, Zachmann M, Prader A: Treatment with human growth hormone in patients with Prader-LabhartWilli syndrome reduces body fat and increases muscle mass and physical performance. Eur J Pediatr 1998;157:368-377.

18 Eiholzer U, l'Allemand D: Growth hormone normalises height, prediction of final height and hand length in children with PraderWilli syndrome after four years of therapy. Horm Res 2000;53:185-192.

19 Eiholzer U, Whitman BY: A comprehensive team approach to the management of patients with Prader-Willi syndrome. J Pediatr Endocrinol Metab 2004;17:1153-1175.

-20 Schlumpf M, Eiholzer U, Gygax M, Schmid S, van der Sluis I, l'Allemand D: A daily comprehensive muscle training programme increases lean mass and spontaneous activity in children with Prader-Willi syndrome after 6 months. J Pediatr Endocrinol Metab 2006;19:65-74.

-21 Bray G, Dahms W, Swerdloss R, Fiser R, Atkinson R, Carrel X: The Prader-Willi syndrome. A study of 40 patients and a review of the literature. Medicine 1983;62:59-80.

-22 Wollmann HA, Schultz U, Grauer M, Ranke $\mathrm{M}$ : Reference values for height and weight in Prader-Willi syndrome based on 315 patients. Eur J Pediatr 1998;157:634-642.

-23 Schoeller D, Levitsky L, Bandini L, Dietz W, Walczak A: Energy expenditure and body composition in Prader-Willi syndrome. Metabolism 1988;37:115-120.

-24 Lindgren AC, Hagenas L, Ritzen EM: Growth hormone treatment of children with PraderWilli syndrome: effects on glucose and insulin homeostasis. Horm Res 1999;51:157161.
25 l'Allemand D, Eiholzer U, Schlumpf M, Torresani T, Girard J: The carbohydrate metabolism is not impaired after 3 years of growth hormone therapy in children with PraderWilli syndrome. Horm Res 2003;59:239248.

26 Ritzen EM: Endocrine physiology and therapy in Prader-Willi syndrome; in Cassidy SB (ed): Prader-Willi Syndrome and Other Chromosome 15q Deletion Disorders. New York, Springer, 1992, pp 153-169.

27 Crino A, Schiaffini R, Ciampalini P, Spera S, Beccaria L, Benzi F, Bosio L, Corrias A, Gargantini L, Salvatoni A, Tonini G, Trifiro G, Livieri C: Hypogonadism and pubertal development in Prader-Willi syndrome. Eur J Pediatr 2003;162:327-333.

28 Dykens EM, Leckman JF, Cassidy SB: Obsessions and compulsions in Prader-Willi syndrome. J Child Psychol Psychiatry 1996;37: 995-1002.

29 Dimitropoulos A, Feurer ID, Roof E, Stone W, Butler MG, Sutcliffe J, Thompson T: Appetitive behavior, compulsivity, and neurochemistry in Prader-Willi syndrome. Ment Retard Dev Disabil Res Rev 2000;6:125130.

30 Dykens EM, Hodapp RM, Walsh K, Nash LJ: Profiles, correlates, and trajectories of intelligence in Prader-Willi syndrome. J Am Acad Child Adolesc Psychiatry 1992;31: 1125-1130.

31 Clarke DJ, Boer H, Whittington J, Holland A, Butler J, Webb T: Prader-Willi syndrome, compulsive and ritualistic behaviours: the first population-based survey. Br J Psychiatry 2002;180:358-362.

32 Boer H, Holland A, Whittington J, Butler J, Webb T, Clarke D: Psychotic illness in people with Prader Willi syndrome due to chromosome 15 maternal uniparental disomy. Lancet 2002;359:135-136.

33 Vogels A, De Hert M, Descheemaeker MJ, Govers V, Devriendt K, Legius E, Prinzie P, Fryns JP: Psychotic disorders in Prader-Willi syndrome. Am J Med Genet A 2004;127: 238-243.

34 Steinhausen HC, Eiholzer U, Hauffa BP, Malin Z: Behavioural and emotional disturbances in people with Prader-Willi syndrome. J Intellect Disabil Res 2004;48:4752.

35 Prader A, Largo R, Molinari L, Issler C: Physical growth of Swiss children from birth to 20 years of age. Helv Paediatr Acta Suppl 1989;52:1-125.
36 Greulich W, Pyle S: Radiographic Atlas of the Development of the Hand and Wrist. Stanford, Stanford University Press, 1959

37 Boot AM, Bouquet J, de Ridder MA, Krenning EP, De Muinck K: Determinants of body composition measured by dual-energy $\mathrm{X}$-ray absorptiometry in Dutch children and adolescents. Am J Clin Nutr 1997;66:232238

38 l'Allemand D, Eiholzer U, Schlumpf M, Steinert H, Riesen W: Cardiovascular risk factors improve under 3 years of growth hormone therapy in Prader-Willi syndrome. Eur J Pediatr 2000;159:835-842.

39 l'Allemand D, Eiholzer U, Rousson V, Girard J, Blum WF, Torresani T, Gasser T: Increased adrenal androgens in Prader-Willi syndrome are associated with insulin, IGF-I and leptin, but not with measures of obesity. Horm Res 2002;58:215-222.

40 Zachmann M: Evaluation of gonadal function in childhood and adolescence. Helv Paediatr Acta 1974;suppl 34:53-62.

41 Carrel AL, Myers SE, Whitman BY, Allen DB: Benefits of long-term GH therapy in Prader-Willi syndrome: a 4-year study. J Clin Endocrinol Metab 2002;87:1581-1585.

42 Dykens EM, Cassidy SB: Prader-Willi syndrome. Genetic, behavioural and treatment issues. Child Adolesc Psychiatr Clin N Am 1996;5:193-927.

43 Steinhausen HC, Eiholzer U, Hauffa BP, Malin Z: Behavioural and emotional disturbances in people with Prader-Willi syndrome. J Intellect Disabil Res 2004;48: 47-52.

44 Burd L, Vesely B, Martsolf J, Korbeshian J: Prevalence study of Prader-Willi syndrome in North Dakota. Am J Med Genet 1990;37: 97-99.

45 Whittington JE, Holland AJ, Webb T, Butler J, Clarke D, Boer H: Population prevalence and estimated birth incidence and mortality rate for people with Prader-Willi syndrome in one UK Health Region. J Med Genet 2001; 38:792-798.

-46 Bourguignon JP: Linear growth as a function of age at onset of puberty and sex steroid dosage: therapeutic implications. Endocr Rev 1988;9:467-488.

47 Pope HG Jr, Kouri EM, Hudson JI: Effects of supraphysiologic doses of testosterone on mood and aggression in normal men: a randomized controlled trial. Arch Gen Psychiatry 2000;57:133-140.

48 Weiss EL, Bowers MB Jr, Mazure CM: Testosterone-patch-induced psychotic mania. Am J Psychiatry 1999; 156:969.

49 Hartgens F, Kuipers H: Effects of androgenic-anabolic steroids in athletes. Sports Med 2004;34:513-554. 